\title{
Efficacy of NiTi rotary instruments in removing calcium hydroxide dressing residues from root canal walls
}

\begin{abstract}
Milton Carlos Kuga(a)
Edson Alves de Campos ${ }^{(a)}$

Norberto Batista de Faria-Junior ${ }^{(a)}$

Marcus Vinicius Reis Só(b)

André Luis Shinohara(c)
\end{abstract}

(a) Department of Restorative Dentistry, Faculdade de Odontologia de Araraquara, Unesp - Univ Estadual Paulista, Araraquara, SP, Brazil.

(b) Department of Endodontics, School of Dentistry, Universidade Federal do Rio Grande do Sul, Porto Alegre, RS, Brazil.

(c)Department of Biological Sciences, Bauru Dental School, Universidade de São Paulo USP, Bauru, SP, Brazil.

Declaration of Interests: The authors certify that they have no commercial or associative interest that represents a conflict of interest in connection with the manuscript.

Corresponding Author:

Milton Carlos Kuga

E-mail:kuga@foar.unesp.br

Received for publication on Sep 16, 2011 Accepted for publication on Dec 07, 2011

\begin{abstract}
The aim of this study was to evaluate the efficacy of three rotary instrument systems (K3, ProTaper and Twisted File) in removing calcium hydroxide residues from root canal walls. Thirty-four human mandibular incisors were instrumented with the ProTaper System up to the F2 instrument, irrigated with $2.5 \% \mathrm{NaOCl}$ followed by $17 \%$ EDTA, and filled with a calcium hydroxide intracanal dressing. After 7 days, the calcium hydroxide dressing was removed using the following rotary instruments: G1 - NiTi size 25, 0.06 taper, of the K3 System; G2 - NiTi F2, of the ProTaper System; or G3 - NiTi size 25, 0.06 taper, of the Twisted File System. The teeth were longitudinally grooved on the buccal and lingual root surfaces, split along their long axis, and their apical and cervical canal thirds were evaluated by SEM $(\times 1000)$. The images were scored and the data were statistically analyzed using the Kruskall Wallis test. None of the instruments removed the calcium hydroxide dressing completely, either in the apical or cervical thirds, and no significant differences were observed among the rotary instruments tested $(\mathrm{p}>0.05)$.
\end{abstract}

Descriptors: Endodontics; Calcium Hydroxide; Dentin.

\section{Introduction}

Calcium hydroxide has been widely used in endodontics. Various biological properties have been attributed to this substance, such as antimicrobial activity, ${ }^{1}$ high alkalinity, ${ }^{2}$ inhibition of tooth resorption, ${ }^{3}$ and tissue-dissolving ability. ${ }^{4}$ To be effective, it has to be adequately placed and condensed in the root canal space. ${ }^{5}$ However, before the root canal can be filled, the dressing on the canal must first be removed. ${ }^{6}$ Calcium hydroxide residues on the canal walls interfere negatively in endodontic treatment prognosis, ${ }^{7}$ influence dentine bond strength ${ }^{8}$ affect the adhesion of the endodontic filling material to the root canal walls ${ }^{9}$ and the penetration of sealers into dentinal tubules, ${ }^{10}$ and react chemically with the sealer, interfering with its physical properties. ${ }^{11,12}$

Several techniques have been proposed to remove the calcium hydroxide dressing from the root canal system, including the use of endodontic hand files, ${ }^{13}$ sonic activation, ${ }^{14}$ passive ultrasonic irrigation, ${ }^{6,15}$ the CanalBrush System ${ }^{6}$ and nickel-titanium rotary instruments. ${ }^{16,17}$ Removal of the dressing using hand files, with or without an irrigating solution, may be inefficient and tedious, ${ }^{6}$ whereas the use of NiTi rotary instruments may enhance the removal procedure when compared to the techniques 
using hand files. ${ }^{16}$

Three designs of NiTi rotary instruments have been introduced in the market:

- the ProTaper System (Dentsply Maillefer, Ballaigues, Switzerland),

- the K3 System (Sybron Dental Specialties, Orange, USA) and

- the Twisted Files System (Sybron Dental Specialties, Orange, USA).

These systems are used in endodontic treatment for the cleaning and shaping of root canals. ProTaper instruments are characterized by a convex triangular cross-section, progressively increasing tapers, and a modified guiding tip. ${ }^{18}$ The K 3 instruments are characterized by a variable core diameter and three asymmetrical radial lands, with a slightly positive angle, two of which are broad and the third is narrow. ${ }^{19}$ The Twisted File instrument was developed through a different manufacturing process, ${ }^{20}$ in that it has a twisted design, a surface de-oxidation treatment, a triangular cross-section, variable pitch and a safe-ended tip. ${ }^{21}$ However, no studies have been published comparing these systems as to their efficacy in removing calcium hydroxide residues from root canal walls.

The aim of this study was to compare the efficacy of the K3, ProTaper, and Twisted File systems in removing calcium hydroxide residues from root canal walls in the apical and cervical thirds of extracted teeth using scanning electron microscopy $(\times 1000)$.

\section{Methodology}

Thirty-four extracted human permanent mandibular incisors measuring $20 \pm 0.5 \mathrm{~mm}$ in length, stored in a $0.1 \%$ thymol solution, were obtained from a tooth bank for this study. The present study was approved by the University Research Ethics Committee (60.0.199.000.11/FOAr-UNESP).

After obtaining coronal access with a \#1012 diamond bur (KG Sorensen, São Paulo, SP, Brazil), the cervical and middle thirds of each tooth were prepared using S1 and SX instruments (ProTaper System; Dentsply Maillefer, Ballaigues, Switzerland). The working length was established $1.0 \mathrm{~mm}$ short of the total tooth length and confirmed radiographi- cally. All canals were prepared by the same operator using the ProTaper System up to the F2 instrument. ${ }^{22}$ Irrigation was performed conventionally with $1 \mathrm{~mL}$ of $2.5 \% \mathrm{NaOCl}$ (Asfer, São Caetano do Sul, Brazil) after using each instrument, by way of a 5-mL disposable syringe with 27-gauge needle (Endo Eze ${ }^{\circledR}$ Irrigator; Ultradent Products Inc., South Jordan, USA). Final irrigation was done with $5 \mathrm{~mL}$ of $2.5 \% \mathrm{NaOCl}$ and $5 \mathrm{~mL}$ of $17 \%$ EDTA (Biodinâmica, Ibiporã, Brazil). The solutions were aspirated with a green Navitip point (Ultradent Products Inc., South Jordan, USA), and the canals were dried with absorbent paper points. The canals were then filled with a calcium hydroxide (Biodinâmica. Ibiporã, Brazil) and propylene glycol (Synth, Diadema, Brazil) paste using a lentulo spiral (Dentsply Maillefer, Ballaigues, Switzerland), at a powder-to-liquid ratio of $1 \mathrm{~g}: 1.5 \mathrm{~mL} .{ }^{23}$ Radiographs were taken of each root to confirm their complete filling with calcium hydroxide paste. The teeth used for negative control $(\mathrm{n}=2)$ received no calcium hydroxide intracanal dressing, and those used for positive control $(n=2)$ received the intracanal dressing, but no following removal procedure was carried out.

The coronal access cavities were sealed with a layer of gutta-percha followed by IRM (Dentsply Ind. Com. Ltda., Petrópolis, Brazil). All specimens were kept in a closed container, and specimen roots were placed in a moist environment for 7 days at $37^{\circ} \mathrm{C}$. After this period, the coronal access was reopened and the canal was irrigated with $5 \mathrm{~mL}$ of a $2.5 \% \mathrm{NaOCl}$ solution.

Thirty specimens were randomly divided into 3 experimental groups $(\mathrm{n}=10)$, according to the rotary instrument used to remove the dressing:

- G1 - K3 Endo instrument size 25, 0.06 taper;

- G2 - ProTaper F2 instrument;

- G3 - Twisted File instrument size 25, 0.06 taper.

The rotary instruments were applied using an electric motor (X-Smart; Dentsply Maillefer, Ballaigues, Switzerland), driven at $250 \mathrm{rpm}$ and with a torque of $1.6 \mathrm{~N} / \mathrm{cm}$. Final irrigation was done with $5 \mathrm{~mL}$ of $2.5 \% \mathrm{NaOCl}$. The solutions were aspirated and the canals were dried with absorbent paper points. Next, grooves were made on the buccal and 
lingual surfaces of the teeth with a water-cooled diamond disc, and the teeth were split along their long axis in a buccolingual direction using a surgical chisel. For SEM analysis, the specimens were dehydrated, fixed on aluminum stubs, sputter-coated with gold, and examined under a scanning electron microscope (JEOL, Tokyo, Japan). Several photomicrographs $(\times 1000)$ were taken to observe the calcium hydroxide residues at the apical (2-3 $\mathrm{mm}$ from the apex) and cervical (10-12 mm from the apex) thirds of each specimen. These areas were evaluated by three independent examiners. The images were scored according to the following criteria given by Kuga et al.: ${ }^{17}$

- 0 - absence of residues,

- 1 - small amount of residues (up to $20 \%$ of the surface covered),

- 2 - moderate amount of residues $(20 \%$ to $60 \%$ of the surface covered), and

- 3 - large amount of residues (more than $60 \%$ of the surface covered).

The scores were assigned to the apical and cervical thirds independently. The data obtained were analyzed statistically by the Kruskal-Wallis test at a significance level of $5 \%$.

\section{Results}

Remnants of calcium hydroxide dressing were found in all experimental groups regardless of the instrument used for removal. Table 1 shows the rank means of each experimental group, in the apical and cervical root canal thirds. No significant differences were observed between the different rotary instruments tested, irrespective of the root canal third considered ( $p>0.05)$. SEM micrographs representative of the calcium hydroxide residues $(\times 1000)$ ob-

Table 1 - Rank means in the experimental groups, regarding the presence of calcium hydroxide residues at the apical and cervical canal thirds.

\begin{tabular}{c|c|c|c}
\hline & K3 & Pro Taper & Twisted File \\
\hline Apical & 14.55 & 16.40 & 17.75 \\
\hline Cervical & 14.35 & 16.25 & 15.70 \\
\hline
\end{tabular}

* No statistical difference was observed between the groups ( $p>0.05)$. served for G1 (K3), G2 (ProTaper) and G3 (Twisted File) in the apical (A, B and C) and cervical (D, E and F) thirds, respectively, are shown in Figure 1. The images revealed extensive coverage of the dentin canal wall in all thirds.

\section{Discussion}

Several studies have shown that the presence of calcium hydroxide on dentin walls can affect endodontic treatment success. ${ }^{7,8,11}$ It has been reported that residual calcium hydroxide interacts with zinc oxide-eugenol sealers to produce calcium eugenolate. ${ }^{11}$ The residues could also influence the adhesion of sealers to the root canal walls, ${ }^{9,10}$ compromising the quality of the seal provided by the root filling. ${ }^{24,25}$ The dressing can be removed by irrigating the canal with $\mathrm{NaOCl}$, EDTA or citric acid ${ }^{13,26,27}$ in conjunction with manual files, ${ }^{13}$ passive ultrasonic irrigation, ${ }^{6,15}$ sonic activation, ${ }^{14}$ the CanalBrush system, ${ }^{6}$ or rotary instruments. ${ }^{17}$

In the present study, a paste of calcium hydroxide with propylene glycol was used. According to the related literature, the paste composition does not influence the efficiency of mechanical and/or chemical methods in removing residues from root canal walls. ${ }^{13,28}$ The final irrigation with $2.5 \% \mathrm{Na}$ $\mathrm{OCl}$ was chosen because $17 \%$ EDTA and $\mathrm{NaOCl}$ are equally effective for the removal of calcium hydroxide when rotary instruments are used. ${ }^{6,17}$ Various methods have been used in endodontic research to investigate the amount of residues on the canal walls. In our study, scanning electron microscopy was used at $\times 1000$ magnification and the calcium hydroxide residues were evaluated using a scoring method similar to that used in other studies. ${ }^{17,26,27}$

We failed to remove calcium hydroxide residues completely from the canal walls under the conditions tested, regardless of the rotary instrument used, and dressing remnants were found in the apical and cervical thirds. This finding agrees with those of previous studies showing residues on the root canal walls, regardless of the removal technique used. ${ }^{6,15,16,27-29}$

To date, few studies have evaluated the influence of rotary instruments on dressing removal. Kenee et al. ${ }^{16}$ evaluated the amount of calcium hydroxide 

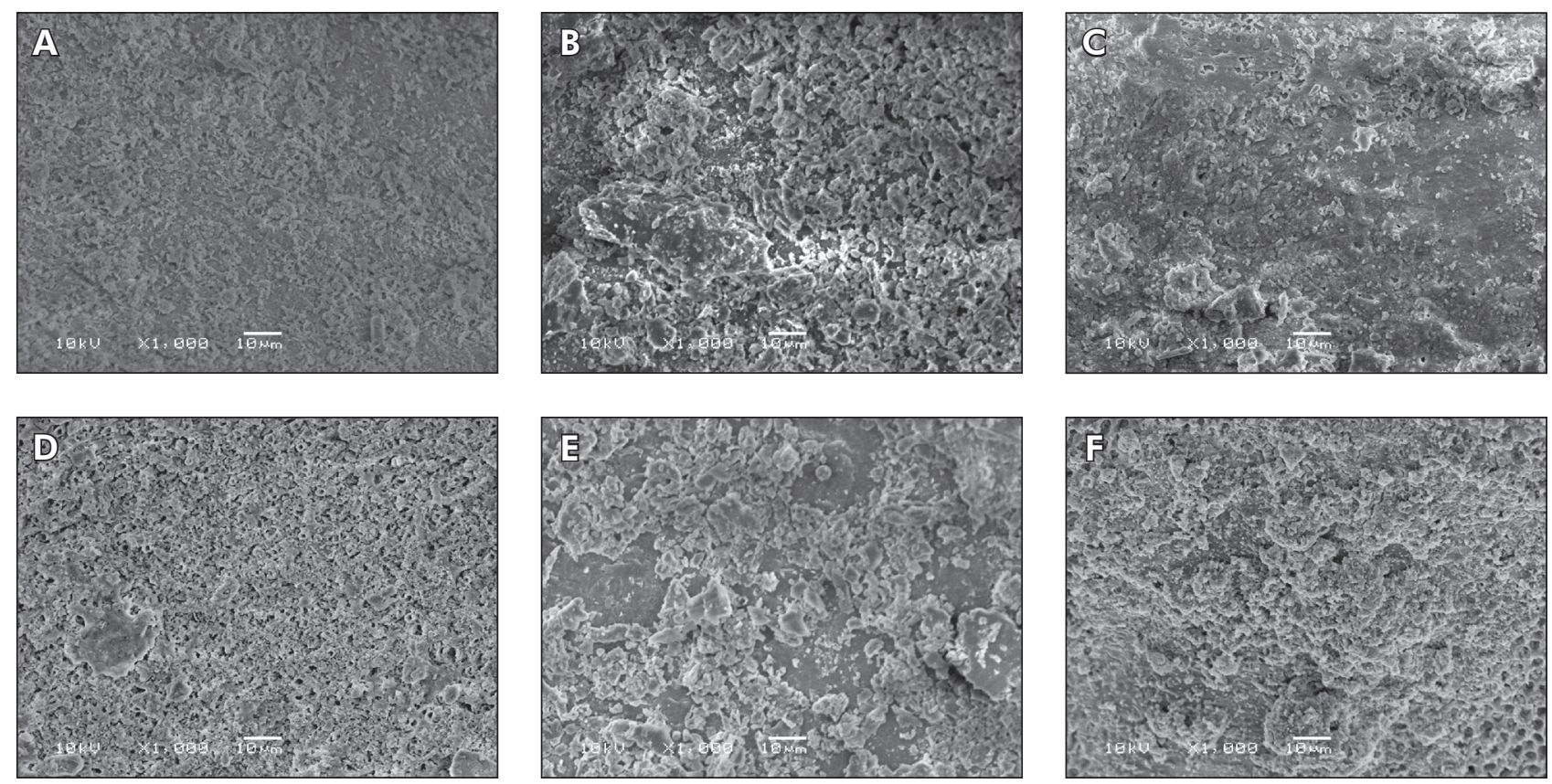

Figure 1 - SEM micrographs (×1000) representative of G1 - K3 system, instrument size 25, 0.06 taper $(\mathbf{A}=$ apical third; $\mathbf{D}=$ cervical third), G2 - ProTaper system, F2 instrument (B = apical third; $\mathbf{E}=$ cervical third), and G3 - Twisted File system, instrument size 25, 0.06 taper $(\mathbf{C}=$ apical third; $\mathbf{F}=$ cervical third).

remaining in mesial canals of molars after removal with $\mathrm{NaOCl}$ and EDTA irrigation, hand files (size 35), rotary instrumentation (Profile System, instrument size 35, 0.04 taper) or ultrasonics (using a size 15 file). They found that rotary and ultrasonic techniques removed significantly more residues than the hand file and irrigating solution techniques. Kuga et al. ${ }^{17}$ evaluated the efficacy of the F1 instrument of the ProTaper system, and instrument size 25, 0.06 taper of the K3 System, combined with $\mathrm{NaOCl}$ or EDTA, in removing calcium hydroxide from root canal dentin walls. They found that, the F1 instrument performed better in the apical and cervical thirds than the K3 instrument, size 25, 0.06 taper, regardless of the final irrigating solution.

Nevertheless, the results of the present investigation revealed that the efficiency of the three rotary

\section{References}

1. Soares JA, Leonardo MR, Silva LAB, Tanomaru-Filho M, Ito IY. Effect of rotary instrumentation and of the association of calcium hydroxide and chlorhexidine on the antisepsis of the root canal system in dogs. Braz Oral Res. 2006 Apr-Jun;20(2):120-6. systems tested was similar, and none guaranteed the complete removal of calcium hydroxide residues. This data may be explained by instrument adaptation to the root canal, insofar as the instrument size 25, 0.06 taper of either the K3 or the Twisted File systems, both in D0 and D16, has a similar taper to that of the F2 instrument of the ProTaper System, irrespective of the design and the variable taper of the rotary instrument.

\section{Conclusion}

Under the conditions of this study, it was concluded that none of the instruments tested completely removed calcium hydroxide residues from the root canal walls. Analysis of the apical and cervical thirds did not detect significant differences among the K3, ProTaper and Twisted File systems.

2. Mori GG, Ferreira FC, Batista FRS, Godoy MAS, Nunes DC. Evaluation of the diffusion capacity of calcium hydroxide pastes through the dentinal tubules. Braz Oral Res. 2009 Apr-Jun;23(2):113-8. 
3. Negri MR, Panzarini SR, Poi WR, Sonoda CK, Gulinelli JL, Saito CTMH. Analysis of the healing process in delayed tooth replantation after root canal filling with calcium hydroxide, Sealapex and Endofill: a microscopic studt in rats. Dent Traumatol. 2008 Dec;24(6):645-50.

4. de la Casa ML, Salas MM, Lópes ME, Raiden G. Protein content in irrigation solutions in contact with pulp tissue. Acta Odontol Latinoam. 2008 Jul;21(1):65-8.

5. Zmener O, Pameijer CH, Banegas G. An in vitro study of the $\mathrm{pH}$ of three calcium hydroxide dressing materials. Dent Traumatol. 2007 Feb;23(1):21-5.

6. Taşdemir T, Çelik D, Er K, Yildrim T, Ceyhanli KT, Yeşilyurt C. Efficacy of several techniques for the removal of calcium hydroxide medicament from root canals. Int Endod J. 2011 Jun; 44(6):505-9.

7. Ricucci D, Langeland K. Incomplete calcium hydroxide removal from the root canal: a case report. Int Endod J.1997 Nov;30(6):418-1.

8. Windley W, Ritter A, Trope M. The effect of short-term calcium hydroxide treatment on dentin bond strengths to composite resin. Dent Traumatol. 2003 Apr;19(2):79-84.

9. Barbizam JV, Trope M, Teixeira EC, Tanomaru-Filho M, Teixeira FB. Effect of calcium hydroxide intracanal dressing on the bond strength of a resin-based endodontic sealer. Braz Dent J. 2008 Jul-Sep;19(3): 224-7.

10. Çalt $S$, Serper A. Dentinal tubule penetration of root canal sealers after root canal dressing with calcium hydroxide. J Endod. 1999 Jun;25(6):431-3.

11. Margelos J, Eliades G, Verdelis C, Palaghias G. Interaction of calcium hydroxide with zinc oxide-eugenol type sealers: a potential clinical problem. J Endod. 1997 Jan;23(1):43-8.

12. Hosoya N, Kurayama H, Iino F, Arai T. Effects of calcium hydroxide on physical and sealing properties of canal sealers. Int Endod J. 2004 Mar;37(3):178-84.

13. Lambrianidis T, Kosti E, Boutsioukis C, Mazinis M. Removal efficacy of various calcium hydroxide/chlorhexidine medicaments from the root canal. Int Endod J. 2006 Jan;39(1):55-61.

14. Wiseman A, Cox TC, Paranjpe A, Flake NM, Cohenca N, Johnson JD. Efficacy of sonic and ultrasonic activation for removal of calcium hydroxide from mesial canals of mandibular molars: a microtomographic study. J Endod. 2011 Feb;37(2):235-8.

15. Van der Sluis LWM, Wu MK, Wesselink PR. The evaluation of removal of calcium hydroxide paste from an artificial standardized groove in the apical root canal using different irrigation methodologies. Int Endod J. 2007 Jan;40(1):52-7.

16. Kenee DM, Allemang JD, Johnson JD, Hellstein J, Nichol BK. A quantitative assessment of efficacy of various calcium hydroxide removal techniques. J Endod. 2006 Jun;32(6):5635.
17. Kuga MC, Tanomaru-Filho M, Faria G, Só MV, Galletti T, Bavello JR. Calcium hydroxide intracanal dressing removal with different rotary instruments and irrigating solutions: a scanning electron microscopy study. Braz Dent J. 2010 JulAug;21(4):310-4.

18. Saad AY, Al-Hadlaq SM, Al-Katheeri NH. Efficacy of two rotary NiTi instruments in the removal of gutta-percha during root canal retreatment. J Endod. 2007 Jan;33(1):38-41.

19. Melo MCC, Pereira ESJ, Viana ACD, Fonseca AMA, Buono VTL, Bahia MGA. Dimensional characterization and mechanical behaviour of K3 rotary instruments. Int Endod J. 2008 Apr;41(4):329-38.

20. Gambarini G, Gerosa R, De Luca M, Garala M, Testarelli L. Mechanical properties of a new and improved nickel-titanium alloy for endodontic use: an evaluation of file flexibility. Oral Surg Oral Med Oral Pathol Oral Radiol Endod. 2008 Jun;105(6):798-800.

21. Marfisi K, Mercade M, Plotino G, Duran-Sindreu F, Bueno R, Roig M. Efficacy of three different rotary files to remove gutta-percha and Resilon from root canals. Int Endod J. 2010 Nov;43(11):1022-8.

22. De-Deus G, Barino B, Zamolyi RQ, Souza E, Fonseca Jr A, Fidel S, et al. Suboptimal debridement quality produced by the single-file F2 Protaper technique in oval-shaped canals. J Endod. 2010 Nov;36(11):1897-900.

23. Estrela C, Holland R, Bernabe PF, de Souza V, Estrela CR. Antimicrobial potential of medicaments used in healing process in dogs' teeth with apical periodontitis. Braz Dent J. 2004 Sep-Dec;15(3):181-5.

24. Kontakiotis EG, Wu MK, Wesselink PR. Effect of calcium hydroxide dressing on seal of permanent root filling. Endod Dent Traumatol. 1997 Dec;13(6):281-4.

25. Kim SK, Kim YO. Influence of calcium hydroxide intracanal medication on apical Seal. Int Endod J. 2002 Jul;35(7):623-8.

26. Salgado RJC, Moura-Netto C, Yamazaki AK, Cardoso LN, Moura AAM, Prokopowitsch I. Comparison of different irrigants on calcium hydroxide medication removal: microscopic cleanliness evaluation. Oral Surg Oral Med Oral Pathol Oral Radiol Endod. 2009 Apr;107(4):580-4.

27. Rödig T, Vogel S, Zapf A, Hülsmann M. Efficacy of different irrigants in the removal of calcium hydroxide from root canals. Int Endod J. 2010 Jun;43(6):519-527.

28. Balvedi RP, Versiani MA, Manna FF, Biffi JC. A comparison of two techniques for the removal of calcium hydroxide from root canals. Int Endod J. 2010 Sep;43(9):763-8.

29. Rödig T, Hirschleb M, Zapf A, Hülmann M. Comparison of ultrasonic irrigation and RinsEndo for the removal of calcium hydroxide and Ledermix paste from root canal. Int Endod J. 2011 Dec;44(12):1155-61. doi: 10.1111/j.13652591.2011.01937.x. Epub 2011 Sep 13. 